\title{
Contar la crisis: materiales narrativos en la semántica social de la crisis
}

\author{
Ramón RAMOS TORRE \\ TRANSOC - Universidad Complutense de Madrid \\ rrt@cps.ucm.es
}

Recibido: 09-06-2015

Aceptado: 08-02-2016

\section{Resumen}

Basado en la evidencia proporcionada por 9 grupos de discusión, este trabajo aborda la semántica social de la crisis en el marco de la hipótesis propuesta por Janet Roitman. En consecuencia propone retratar distintas estrategias narrativas que permiten dar cuenta de la experiencia de la crisis según cuatro ejes de contraposiciones: agencia/paciencia, moralización/poder, coyuntura/cronicidad, destrucción/creación. En su parte final, propone fijar los rasgos fundamentales de los sujetos que aparecen en seno de las tramas narrativas propuestas

Palabras clave: crisis; semántica social; modernidad; narración.

\section{Telling the Crisis: Narrative Elements in the Social Semantics of Crisis}

\begin{abstract}
Based on the evidence provided by 9 focus groups, this paper deals with social semantics of the crisis within the framework of the hypothesis proposed by Janet Roitman. It proposes to portray various narrative strategies that allow to give account of the experience of the crisis, according to four axes of contrasts: Agency/patience, moralizing/power, situation/chronicity, destruction/creation. At its end, it proposes to reconstruct the fundamental features of the subjects appearing inside the proposed narrative plots.

Key words: crisis; social semantics; modernity; narrative.
\end{abstract}

\section{Referencia normalizada}

Ramos Torre, R. (2016): "Contar la crisis: materiales narrativos en la semántica social de la crisis", Política y Sociedad, 53 (2), pp. 331-352.

Sumario: 1. De la sociología de la crisis a la crisología. 2. De la crisología a la narración. 3. Repertorios de sentido a la mano y matrices narrativas de la crisis. 4. Los sujetos de la narración. 5. Conclusiones. 6. Bibliografía.

$$
* * *
$$

\section{Agradecimientos}

Este trabajo se enmarca en la investigación "Riesgo, incertidumbre y vulnerabilidad en España" (CSO2010-20235) desarrollada por Ramón Ramos (IP) y Javier Callejo (y a partir de enero de 2014, también por José Antonio Santiago) en el marco del Plan Nacional de I+D+i de la Secretaría 
de Estado de Investigación, Desarrollo e Innovación del $\mathrm{M}^{\mathrm{o}}$ de Economía y Competitividad. Debe mucho a las reflexiones, recomendaciones y aportaciones directas de Javier Callejo a lo largo de todo el proceso de elaboración. Una primera versión del trabajo fue presentada en el Encuentro de Teoría Sociológica (Bilbao junio 2014); una segunda más desarrollada en el Seminario de Investigación TRANSOC (Madrid diciembre 2014). Agradezco a los intervinientes en ambas reuniones los comentarios realizados, especialmente a José María García Blanco, Fernando García Selgas, Gabriel Gatti, Luis Enrique Alonso, Eduardo Romanos, Ignacio Sánchez de la Yncera, José Antonio Santiago, Benjamín Tejerina y Peter Wagner.

Este trabajo explora la relación entre la crisis y la agencia, pero atendiendo de forma preferente a uno de sus pliegues: ¿qué significa la crisis cuando el actor concibe su experiencia como tal y se pone a contarla?; en concreto, ¿qué significa y qué le significa?, ¿qué cuenta y qué le cuenta? Se centra, pues, la atención en la semántica y la narración de la crisis desde el punto de vista de los actores que la conciben, hacen y padecen, y se hace, como se verá, en el marco de la evidencia acumulada por una investigación que proporciona una rica información ya abordada en otros trabajos en proceso de publicación.

En seguimiento de la temática propuesta, (1) se hará inicialmente una presentación sintética de las sociologías de la crisis, (2) para centrarse a continuación en algunas propuestas que dirigen su atención hacia la narratividad, (3) reconstruir posteriormente un conjunto limitado de matrices narrativas y (4) sujetos narrados, finalizando (5) el recorrido con unas conclusiones.

\section{De la sociología de la crisis a la crisología}

Koselleck (2007 y 2012) ha mostrado de forma convincente el carácter central de la idea de la crisis en la auto-conciencia de la Modernidad. Dado el estatuto de la sociología -desde sus remotos orígenes saint-simonianos- como autoconciencia de una Modernidad sobrevenida, de los sociólogos sería de esperar una atención e interés continuados por el estudio de la crisis. Veremos que esta expectativa se ve en parte frustrada si, más allá de lo que adjetiva a las crisis (sociales, culturales, económicas, psicológicas, mediática, etc.) que se suceden, lo que nos interesa inmediatamente es la crisis en sí misma.

Un somero recorrido por las sociologías más o menos contemporáneas de la crisis permitirá corroborar y especificar lo anterior. En efecto, parecen orientarse en dos direcciones dominantes. La primera las aboca a la guerra de los adjetivos, es decir, a enzarzarse en una disputa epistémico-académica sobre si la crisis que se analiza responde a un tipo preciso o a una combinación de varios. Si es lo primero, la batalla se libra por ubicar la crisis en el propio campo disciplinar (lo social versus lo económico, lo político, lo personal, lo cultural, lo mediático, etc.); una vez ahí ubicada, la tarea consiste en mostrar de qué modo lo social (que difiere de lo económico, cultural, etc.) explica la génesis, desarrollo y eventuales destinos de la crisis. Si es lo segundo, entonces se distinguirán 
las distintas crisis (de nuevo: económica, cultural, de la personalidad, etc.) que se anudan en la crisis, para a continuación analizar la específica coyuntura que conforman y abogar por una perspectiva multidisciplinar que permita un intercambio virtuoso de aportaciones entre disciplinas diferenciadas.

La otra deriva, que viene ya de los tiempos de Saint-Simon (¿cómo se pasa del sistema industrial al "catecismo" de los industriales?), podemos definirla, en los términos de un justamente famoso trabajo de Lockwood, como el problema de las relaciones entre la crisis sistémica y la crisis social. Las distintas líneas de la tradición sociológica se podrían ordenar según se centren mayormente en el aspecto sistémico o en el aspecto social o, como posibilidad más rica, en la relación entre ambos. Combinada con la problemática de si las crisis son epidérmicas, cíclicas o cesurial-revolucionarias, la distinción entre lo sistémico y lo social domina gran parte de las discusiones sobre las crisis en los dos siglos de literatura sociológica.

No entraré en ese territorio de indagación. Poniendo entre paréntesis el interés por los adjetivos que pueden cualificarlo, lo que interesa es el término o sustantivo en sí mismo; más allá de que la crisis sea personal, social, económica, cultural, mediática o de los precios, sea sistémica o social o social-sistémica, lo que interesa por lo pronto es qué se significa cuando se utiliza ese concepto.

Precisamos, pues, una crisología que se centre en esos menesteres. En el campo estricto de la sociología está poco atendida. Un estudioso del tema, Michel Wieviorka (2013: 140), ha señalado los escasos esfuerzos de los sociólogos por aclarar el significado del término que tanto utilizan. De todos los intentos que conozco el más explícito y prometedor es el de Edgar Morin . Sus resultados, sin embargo, son más bien decepcionantes. Morin (1976 y 1995) propone una crisología -es él el padre del término- que dé cuenta de su objeto en el marco del paradigma de la complejidad. Conectado con la tradición MarxFreud, presenta la crisis como reveladora (de lo que estaba oculto o se quería velar) y realizadora (de potencialidades inscritas, pero reprimidas). Más allá, y al hilo de vaivenes y matices constantes que pretenden abarcarlo todo, se limita a sostener que el concepto de crisis anuda (o aporta un espacio de encuentro entre) perturbaciones, desórdenes, incertidumbres, bloqueos de mecanismos de mantenimiento y desbloqueo de mecanismos de contención de posibilidades inhibidas. Este es el núcleo de su propuesta que, más que resolver, confirma lo que ya sabíamos sobre lo propio de la crisis, es decir, el anudamiento de esos (y otros) fenómenos que desbordan la normalidad cotidiana.

\section{De la crisología a la narración}

Desafortunadamente y a pesar de la relevancia sociológica de la crisis, no parece que podamos encontrar en el espacio de la sociología crisologías más sutiles que la de Morin. Para encontrarlas hay que transitar a otros espacios disciplinares -ciertamente muy cercanos. El fundamental es el que se autodenomina de la Historia de los Conceptos. $\mathrm{Su}$ representante es Reinhart Koselleck. En ese campo se desarrollan indagaciones relevantes sobre la semántica histórica de los conceptos propios de la Modernidad. 
Cercano a esa corriente se sitúa el trabajo de Starn (1971) publicado en Past \& Present sobre la significación del concepto de crisis en historiografía desde Tucídides hasta el siglo pasado, artículo breve, pero denso e influyente. Los trabajos de Koselleck y Starn se han desarrollado de forma independiente, o con escasísimas referencias cruzadas. Partiendo de ambos, la muy relevante indagación de Janet Roitman (2014) aborda, en el campo de las discusiones académicas y de expertos (básicamente anglosajones) sobre la crisis económica de 2008-2010, el mismo objetivo de reconstrucción de la semántica de la crisis que Koselleck y Starn realizan en su larga indagación desde los griegos hasta la actualidad. Son de un enorme interés pues en ellos encontramos el objetivo perseguido: una crisología propiamente dicha, que se orienta hacia el problema de la narración.

Me limitaré a presentar una síntesis muy apretada de las propuestas de Koselleck sobre la semántica moderna de la crisis. Centro de su atención desde los tiempos de su tesis doctoral de finales de los años 40, Koselleck ha vuelto sobre el tema en varias ocasiones . Crisis viene del verbo griego kríno, significando separar, escoger, enjuiciar, decidir(se). $\mathrm{Su}$ uso se arraiga en la Cultura Antigua (greco-romana-cristiana) en contextos muy distintos: político- jurídico, teológico y médico, especialmente. De estos tres campos, será el último el más influyente; será decisivo en la introducción del lenguaje de la crisis en los asuntos histórico-sociales de la mano de la exitosa metáfora barroca del 'cuerpo político'.

La tesis de Koselleck es que el concepto de crisis se sitúa en el centro de la Modernidad, convirtiéndose en su "signatura estructural" (Koselleck, 2007: 258) y adquiriendo alta complejidad semántica en el marco de su linaje clásico. Por un lado, atento a su origen médico, crisis va a suponer siempre la aparición de una situación o coyuntura urgente de cambio que, en principio, no puede ser duradera (aunque pueda ser recurrente) y se encamina hacia un final; por otro lado, va a hacer referencia siempre a la relevancia pragmática de lo que se juega en esa situación (la verdad, la salvación, la moral, el derecho, la vida, el bienestar, etc.); además, se subraya la incertidumbre que domina la situación y sus posibles resultados; por último, hay siempre una llamada a la acción en forma de decisión que ha de ser adoptada en condiciones de urgencia, incertidumbre y pragmáticamente cruciales.

Según Koselleck, a lo largo del XIX la idea de la crisis acaba apareciendo en tres variantes: ya sea para hacer referencia al juego de una inestabilidad permanente/ recurrente, ya para significar la transición entre mundos separados por diferencias significativas, ya para anunciar la gran transformación final que en forma de Salvación o Condena acabará con el desosiego; también, como es lógico, es posible encontrar alguna combinación de los tres planos.

La línea que va de Starn (1971) a Shank (2008) es, en principio, más escueta en sus aportaciones. Dejando aparte sus exhibiciones de erudición, la propuesta fundamental consiste en subrayar el carácter metafórico y retórico del concepto tal como se configura en la obra de Tucídides y recoge la tradición que llega hasta nuestros días. Por un lado, se trata de una metáfora médica que enfatiza la enfermedad y permite que el historiador se presente y legitime como el frío científico que observa los asuntos de los humanos. Por el otro, pone en marcha una trama narrativa que los trágicos habían 
desarrollado cumplidamente y Tucídides había incorporado a su relato sobre las guerras entre los griegos. Por esa trama acabamos desembocando en el acontecimiento decisivo que cierra y resuelve el drama, aportando la verdadera significación de lo ocurrido y narrado.

El papel central de la narración en las aproximaciones a la crisis ha vuelto a ser reivindicado recientemente por Janet Roitman (2014). Enlaza con los de Starn y sobre todo Koselleck -que expone brillantemente y al que hace algunas objeciones de calado-, pero se diferencia por abandonar el pasado para ceñirse a la actualidad. Su cometido es reconstruir la polémica de los diagnósticos sobre la crisis económica de 2008-2010 (como crisis bancaria, inmobiliaria, de los nuevos productos financieros, etc.), observando el discurso experto sobre la crisis. Su propuesta es que ese discurso es en realidad el que la crisis genera o hace posible. De este modo, de objeto de análisis y descripción, la crisis se convierte en sujeto o plataforma que hace todos los discursos posibles. Esta interesante hipótesis, la argumenta Roitman en tres pasos consecutivos que le permiten proponer un punto de vista brillante y muy productivo.

El primer paso consiste en resaltar la ubicuidad y universalidad de la crisis. No se trata de que la economía sólo se pueda pensar en términos de crisis, sino que todo lo que se piensa e interpreta en los campos más dispares se hace en esos términos. La crisis -y el acuerdo con Koselleck es aquí máximo- es el rasgo permanente, central, omnipresente de la Modernidad, tanto en su historia como en su actualidad. Ser moderno es estar en crisis, observar el mundo como crisis, abordar la génesis y solución de crisis constantes.

Esto desemboca ineludiblemente en una perplejidad, que constituye el punto de partida del segundo paso de la argumentación. Es la siguiente: si nuestra manera de pensar el mundo insiste en que todo está (o acaba estando) en crisis y es problematizable (carece de fundamentos estables, no puede cumplir sus pretensiones y promesas, etc.) y por lo tanto nada hay seguro o sagrado, ¿por qué la crisis misma, que todo lo problematiza, no es a su vez problematizada?, ¿por qué es un concepto obvio que los críticos utilizan y al que se recurre siempre para contar cualquier cosa?, en definitiva: ¿por qué no está en crisis la crisis? El caso es que no lo está y de ahí la paradoja: todo está en crisis, menos la crisis; es un concepto universal que se aplica a todo, menos a sí mismo; sólo la crisis está exenta de crisis.

La propuesta de Roitman es que se trata de un a priori: lo que nunca se observa porque hace posible toda observación. Más en concreto: es el a priori fundamental de la Modernidad. Y si lo es, entonces resulta que la crisis no es otra cosa que el punto ciego que nos permite observar, pero no puede ser observado:

Crisis is an enabling blind spot for the production of knowledge [...] But if we take crisis to be a blind spot, or a distinction, which makes certain things visible and others invisible, it is merely an a priori. Crisis is claimed, but it remains a latency; it is never itself explained because it allows for the further reduction of "crisis" to other elements, such as capitalism, economy, politics, culture, subjectivity. In that sense, crisis is not a condition to be observed (loss of meaning, alienation, faulty knowled- 
ge); it is an observation that produces meaning. More precisely, it is a distinction that secures "a world" for observation. (Roitman, 2014: 39).

De aquí se llega rápido al tercer paso de la argumentación. Si la crisis es el a priori, el punto ciego desde el que se observa, la plataforma que permite poner en palabras el mundo, ¿qué nos hace disponible o nos pone ante los ojos o nos permite observar?, ¿qué se observa desde la crisis? La respuesta es que la crisis nos sitúa en un mundo a observar por medio de narraciones. En concreto, según Roitman (ibid.: especialmente cap. 2), la crisis actual la reducen y significan los media y los expertos en forma de dos relatos tópicos y recurrentes: el relato del error y el relato de la denuncia.

El primer relato, el del error, da cuenta de lo que está en crisis como resultado de un error institucional o de los agentes; como tal error, es subsanable por medio de la reforma de instituciones y conductas; lo que lleva al barrunto de un happy end cuando se alcance la clarividencia que nos ha faltado hasta ahora. El segundo relato, el de la denuncia de la inmoralidad de un mundo, muestra que la crisis en la que estamos precipitados es el resultado de las carencias morales de las instituciones o de los agentes decisivos en los acontecimientos; supone que, si hubiera una reforma moral, las cosas ocurrirían de manera distintas; y en consecuencia, aventura la reconversión moral del mundo por medio de un nuevo equilibrio.

Hasta aquí Roitman en lo que parece relevante en este contexto de análisis. Me parece del máximo interés su concepción de la crisis como punto ciego de la Modernidad a partir del cual se construyen relatos que los modernos se cuentan a sí mismos. En consecuencia, la relevancia de lo narrativo en los intentos de hacer inteligible la crisis parece una hipótesis del máximo interés. Con todo, su propuesta sobre las dos variantes de relatos de la crisis resulta limitada. En contra, parece más fértil la idea de que la realidad observada como crisis puede dar lugar a relatos variados -no sólo dos, canónicos. En este sentido, sería más interesante explotar la intuición de Starn y Shank -que ubican erróneamente en el campo de la retórica- según la cual la crisis en historiografía dispara la utilización de la trama trágica; el caso de Tucídides sería en este sentido paradigmático. Además, dado que la tragedia es tan sólo una de las tramas posible -como sabemos desde la Poética de Aristóteles-, sería adecuado considerar también otras tramas disponibles y socio-cultural-históricamente recurrentes. En este sentido, sería interesante hacer confluir la hipótesis de Roitman con lo propuesto por Hayden White (1987) en el campo de la historiografía. En este caso, encontraríamos que hay una serie de tramas canónicas (tragedia, comedia, sátira y romance) y podríamos comprobar hasta qué punto los relatos de la crisis se acomodan a su estructura $-\mathrm{y}$ sus variadas moralizaciones del universo narrado . Dada la posible conexión, ya explorada por White, entre la poética de las tramas, la poética de los tropos de lenguaje y la pragmática de los relatos, tal vez de esta manera podríamos unir la metafórica con la narrativa de la crisis. En cualquier caso, es preciso partir de Roitman para ir más allá, mostrando la pluralidad de tramas narrativas que resuelven la problematicidad de un mundo vivido como crisis. 


\section{Repertorios de sentido a la mano y matrices narrativas de la crisis}

En un trabajo sobre la semántica social de la crisis (Ramos y Callejo, pendiente de publicación), he reconstruido el repertorio de sentido a la mano que está a disposición de los hablantes para poner en palabras su experiencia de la crisis. Por repertorio de sentido entiendo el conjunto o colección de las imágenes, ideas, expresiones, barruntos, intuiciones, etc., que en forma de tópicos y contra-tópicos surgen al hilo de las discusiones entre hablantes. Son un repertorio de sentido a la mano porque fijan la colección de sentidos disponibles para actuar en el espacio social de la comunicación. Constituye así el asidero a disposición de todos para poner en palabras las experiencias y las expectativas.

Elmaterial parafijarlo loproporcionanlos resultados de una investigación reciente enla que se realizaron 9 grupos de discusión. El objetivo de la investigación no era inicialmente indagar el discurso social de la crisis, pero éste se acabó mostrando como la única plataforma posible para poder hablar sobre el tema planteado, las expectativas de futuro . Como se aseguraba en uno de los grupos: "Ahora sólo hay crisis" (G7: trabajadores fijos tecno-industriales). Las crisis se mostraba así como la plataforma a partir de la cual era posible hablar de la experiencia, comunicarse con los demás, poner (des)orden y $(\sin )$ sentido en lo que ocurre. Resulta así que, en consonancia con la hipótesis de Roitman, la crisis parece ser a priori o el punto ciego que permite observar y genera narraciones.

En el trabajo antes citado, se propuso que el repertorio de sentido a la mano, lejos de ser caótico o casual, aparecía estructurado en cuatro ejes que se denominaron de la acción, la imputación, la temporalidad y los efectos o consecuencias. En cada uno de estos ejes se contemplan dos posiciones extremas; entre ambas se despliega un espacio continuo en el que se ubican las intervenciones de los hablantes, más o menos cercanas/ lejanas de esos extremos.

El eje de la acción contrapone, utilizando la conocida categorización de Arendt (1993: 213), la agencia y la paciencia. En el polo de la agencia, el repertorio de sentido muestra tópicos que enfatizan la capacidad de decisión-acción de los actores; en el de la paciencia, su situación de seres arrastrados por acontecimientos contextuales no controlados. Por su parte, el eje de la imputación contrasta el polo de la moral con el del poder. Hacia el polo de la moral se orientan todos aquellos tópicos que enfatizan la crisis como castigo de la desmesura (consumista o de otro orden) del pasado inmediato; hacia el extremo del poder, aquéllos que muestran la crisis como hija de los excesos y estrategias de unos pocos (agentes o instituciones) poderosos. El tercer eje, o de la temporalidad, conecta el extremo de lo crónico con el de lo coyuntural o cíclico; en el primero, la crisis se describe como algo estable y permanente que nunca acaba, mientras que en el segundo se presenta como fase coyuntural de un ciclo que arrastrará hacia otras situaciones. Por último, el eje de las consecuencias presenta un extremo en el que se destaca la crisis como destructiva, enfrentado a otro en el que aparece como regenerativa o creativa.

Evidentemente, los ejes unidimensionales se pueden cruzar de dos en dos, generando así un espacio bidimensional en el que habría que situar los distintos elementos que conforman el repertorio de sentido a la mano. Las figuras 1 y 2 visibilizan esa 
posibilidad: la 1 combina el eje de la acción (con sus polos agencia/paciencia) con el de la imputación (y sus polos moral/poder); la 2 combina el eje de la temporalidad (crónico vs cíclico-coyuntural) con el eje de las consecuencias (destrucción/regeneracióncreación). En el espacio bidimensional que configuran, se sitúan los tópicos y contratópicos que forman parte del repertorio de sentido a la mano que los hablantes utilizan.

Figura 1: Cruce Eje 1 (Acción, vertical) y Eje 2 (Imputación, horizontal)

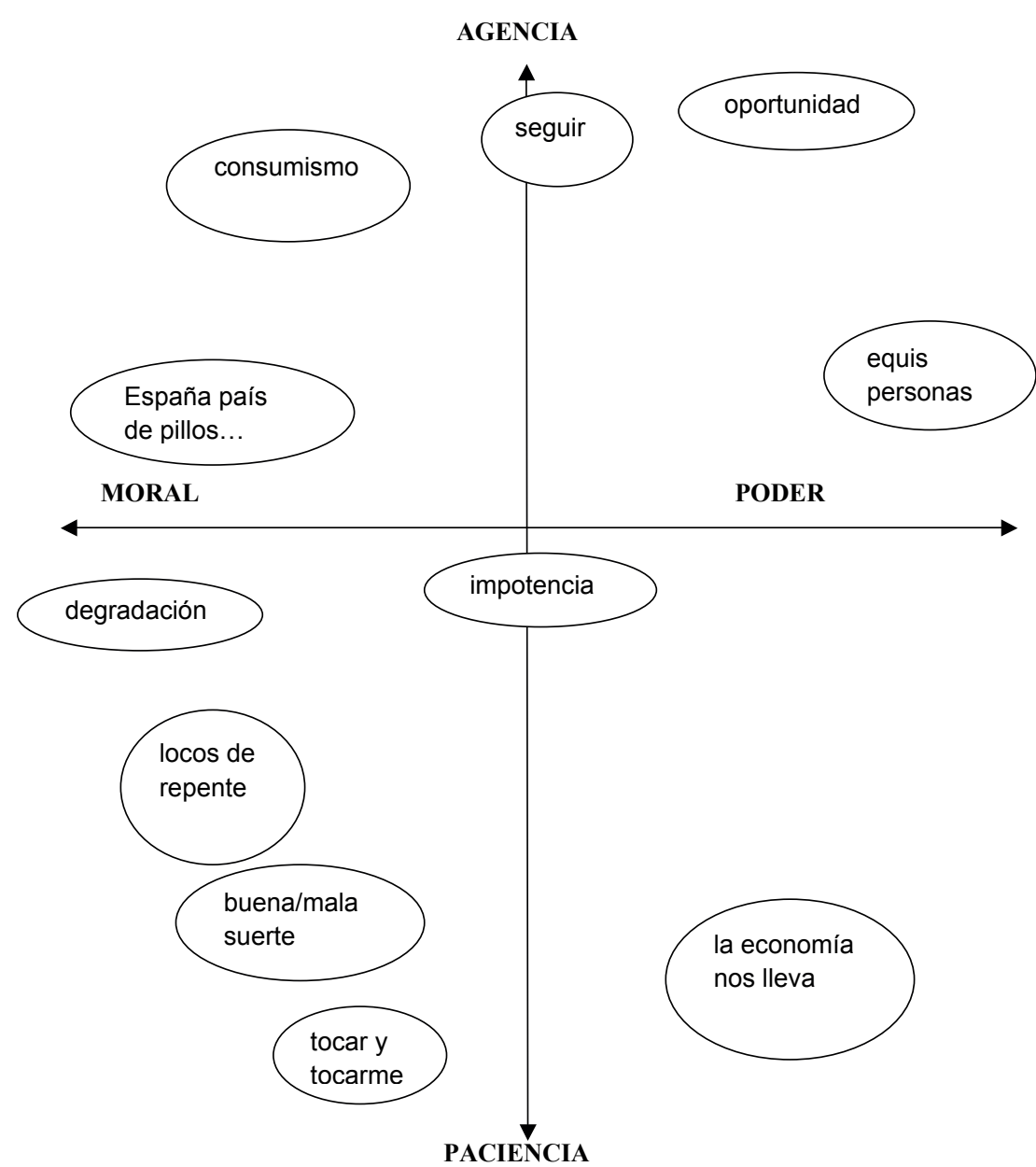

Fuente: Elaboración propia. 
Figura 2: $\quad$ Cruce Eje 3 (Temporalidad, vertical) y Eje 4 (Efectos, horizontal)

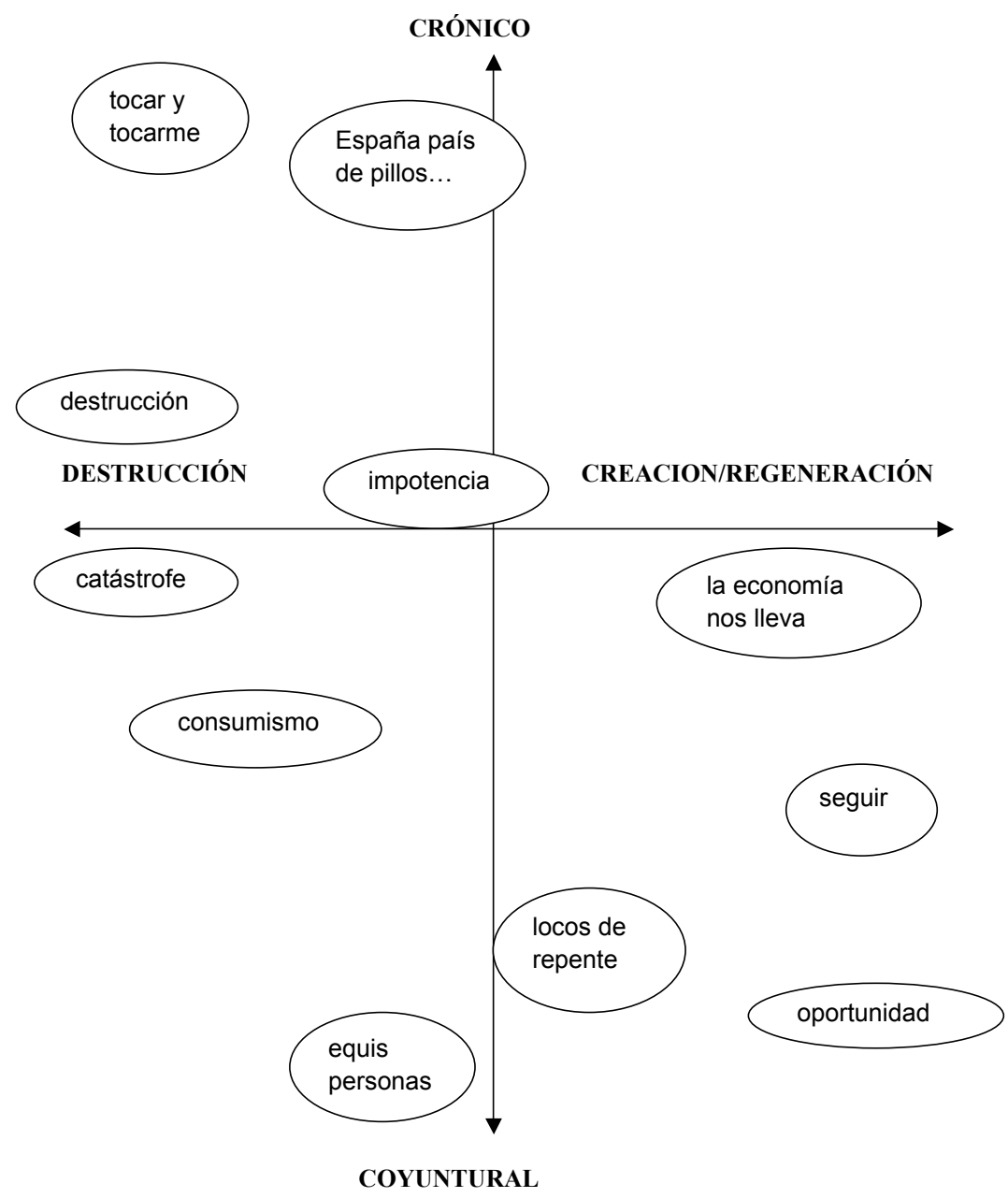

Fuente: Elaboración propia.

En esos dos espacios bidimensionales se han situado algunos de los tópicos recurrentes en la dinámica de los grupos de discusión. Para simplificar su presentación, se ha seleccionado una docena de ellos. Cada uno retrata una intervención situada en el repertorio de sentido que está a la mano de los hablantes. Se procede a una rápida 
ejemplificación, mostrando los verbátim que están por detrás de las denominaciones escogidas (entre paréntesis se especifica el grupo de discusión en el que aprece):

\section{Seguir:}

"Han pasado años y seguimos ahí... no sé.... Pero estamos ahí. Esa es la esperanza que tenemos. De seguir y seguir" (G6).

\section{Oportunidad:}

"es una $[\ldots]$ crisis, pero es una oportunidad..." (G1).

\section{Equis personas:}

"Es decir, mueven los hilos entre equis personas que no sabemos quiénes son, no nos lo quieren decir, y los demás somos como una especie de marionetas.” (G2).

\section{Consumismo:}

"Nos hemos hecho demasiado burgueses" (G6).

"Ese es el quid, no hemos sabido decir que no al que te ponía la bolsa de caramelos en la mano. En vez de coger lo que necesitábamos, se cogía la bolsa. Y ahora la bolsa se ha roto" (G8).

\section{España país de pillos:}

"es que el español es un listo. Entonces mira a ver qué se puede llevar [...] Aquí, el que no hace la trampa dicen... eres tonto. Aquí todo el mundo mira cómo se lo puede llevar y cómo puede engañar y cómo... entonces no cabe esperar otra cosa, estamos donde nos hemos ido...." (G4).

\section{Degradación:}

"pasará como antes, que el que no tiene dinero no podrá ni estudiar y se tendrán que buscar la vida, pues un poco de mala manera... pero lo malo de ahora es que pasará como antes, como estás diciendo,.. pero antes... existían campos, ahora solamente hay cemento... y no funciona... entonces ¿qué van a recoger?, ¿Qué patatas? Así que peor" (G5).

"Como antiguamente... como decía mi padre con los señoritos, dependiendo de los señoritos, o sea, dependiendo de los ricos, ricos" (G6).

\section{Locos de repente:}

"muchísima gente hace unos años que se volvió loca de repente todos eran, venga coches, casas... y era demasiado desmadre, ¿no? y ahora es todo lo contrario. Ha pasado de 100 a $0 . . . . "(G 2)$;

Buena/mala suerte:

"O sea, los que estamos trabajando tenemos una suerte infinita." (G7);

"como no sabes la suerte que puedas tener o no.. te puede ir por un lado, o te puede ir por otro" (G9); 


\section{Tocar y tocarme:}

"en cualquier momento tienes el miedo de decir, bueno, pues el día de mañana me puede tocar a mí. Entonces siempre estás, tienes ese miedo a perder un nivel que más o menos te permite vivir y te permite, tener una cierta calidad de vida. Ves a tu alrededor cosas muy desagradables que están pasando y piensas... bueno, cualquier día ..." (G2);

"seguimos igual, o por lo menos en mi caso seguimos igual, pero piensas.... Por si acaso [...] Mi situación no ha cambiado, pero dices... A ver... no vaya a ser que me toque" (G2);

\section{Impotencia:}

"Sensación de impotencia. Es que me están machacando y resulta que ¿qué puedo hacer?" (G4).

La economía nos lleva:

"La economía, nos tiene que llevar a algo bueno. Ya nos ha llevado a algo malo, pero yo creo que nos tiene que llevar a algo bueno" (G7).

\section{Catástrofe:}

"O sea que... yo creo que algún día esto tiene que explotar" (G5).

"yo creo que esto llegará un momento que por algún lado tenga que estallar... tenga que estallar.... ¿de qué modo?... no tengo ni idea, no sé. Pero esto tiene, que...." (G5).

"pero va a haber un momento que tengamos que reaccionar. Llegara un momento, unas determinadas situaciones algo hay que hacer, algo saldrá y si no, serán nuestros hijos los que líen la de San Quintín" (G5).

"si esto sigue así, la gente va a reventar... la sociedad va a ser impredecible porque van a empezar a asaltar supermercados, a asaltar casas.... Se va a volver loca. Como sigan pasando hambre y dificultades... Ahora les está dando por tirarse por la ventana-el que no se quiera suicidar se va a llevar a alguien por delante..." (G9).

Situados algunos de los elementos del repertorio de sentido a la mano de los hablantes en el espacio bidimensional de las figuras 1 y 2 , podemos dar ya el paso que nos permite aproximarnos a la narración. Es evidente que en las intervenciones en los grupos de discusión no aparecen narraciones compactas en sentido propio, pero resulta también obvio que lo que se dice se presenta ya sea como episodio de una narración disponible, ya como imputable a un personaje que en ella actuara, ya como escenario en la que desplegarla. Es más, la simple combinación de los ejes en los que se sitúan los tópicos y contra-tópicos permite generar un conjunto limitado -pero mucho más rico y variado que el propuesto por Janet Roitman- de matrices narrativas que permiten contar historias en las que van apareciendo los tópicos del repertorio de sentido y en las que se da una salida de ( $\sin )$ sentido a la crisis. Las matrices narrativas fijan las historias posibles que demanda el mundo social como algo observado desde la atalaya de la crisis.

Un primer conjunto de matrices narrativas aparece en el Cuadro 1, en el que se combinan las dos posiciones polares de la acción (agencia/paciencia) con las de las de la imputación (moral/poder). 
Cuadro 1: Acción e Imputación

\begin{tabular}{|c|c|c|}
\hline & Moral & Poder \\
\hline $\mathrm{H}$ & 1.1 & 1.2 \\
$\mathrm{a}$ & & \\
$\mathrm{c}$ & Sanción de la Desmesura & \\
$\mathrm{e}$ & & 1.4 \\
$\mathrm{r}$ & & \\
\hline $\mathrm{P}$ & 1.3 & Crisis sistémica \\
$\mathrm{a}$ & & \\
$\mathrm{d}$ & Crisis cultural & \\
$\mathrm{e}$ & & \\
$\mathrm{c}$ & & \\
$\mathrm{e}$ & & \\
$\mathrm{r}$ & & \\
\hline
\end{tabular}

Fuente: Elaboración propia.

La primera matriz narrativa la denomino de la Sanción de la Desmesura (1.1). Aquí se estructura un posible relato en el que, una vez reconocido que lo ocurrido sólo se nos puede imputar a nosotros y que en este sentido somos culpables, la crisis se nos presenta como una caída que sanciona nuestra desmesura. Cómo se entienda esta desmesura queda abierto a muchas posibilidades -desde luego exploradas de forma muy sistemática por la tragedia ática.

La otra matriz relacionada con la agencia, pero en este caso combinada con la imputación en términos de poder, crea las posibilidades de un relato que parece adecuado denominar de Verdugos y Víctimas (1.2). La propuesta narrativa en este caso arranca de la imputación de lo ocurrido a la acción de agentes poderosos y señalables a los que se responsabiliza de la crisis. Pero siendo sus responsables, no son típicamente sus víctimas. Las víctimas son otros que, disponiendo de menos o nulo poder, saben que lo que sufren no es fruto de sus acciones (víctimas inocentes) e intentan pedir cuenta a los que consideran verdaderos responsables (verdugos). Este juego de víctimas y verdugos estructura relatos recurrentes en nuestros tiempos de crisis.

Las otras dos posibilidades inscritas en el Cuadro 1 toman en consideración la cara oscura de la acción, la paciencia o el padecer. Los actores no se reconocen como agentes de lo ocurrido, ni lo imputan a otros agentes concretos. Hay una sospecha densa que cuestiona la lógica perversa de los sistemas en los que estamos instalados. En la variante de la Crisis Cultural (1.3), el actor vive la crisis como producto de la enfermedad moral del sistema, de una mala conformación cultural que nos convierte en actores movidos por valores (auto-)destructivos (para nosotros, para el bienestar material, para el medio ambiente, para las generaciones futuras, etc.).

Por su parte, en la variante de la Crisis Sistémica (1.4), el relato emergente habla más bien de la existencia de un sistema (nacional o mundial) que funciona por sí mismo 
y sin referencia a ningún objetivo humano consciente; un sistema en el que hay una asimetría estructural entre lo propio de uno de sus subsistemas (el económico, pero también el poder mundial, el imperialismo, etc.) y los restantes, que están sometidos a sus dictados. Prima la lógica narrativa kafkiana o luhmaniana -como la denominaría Beck (1998: caps. III y IV). La crisis es un destino producto de la conformación del sistema; somos arrastrados a ella y seguiremos siéndolo a no ser que se cambie o desaparezca.

Otro conjunto-incluso más relevante e incisivo - de matrices narrativas lo proporciona el Cuadro 2 en el que el cruce de los ejes relacionados con la temporalidad (cronicidad/ coyuntura) y las consecuencias (destrucción/regeneración) permite distinguir cuatro matrices narrativas fundamentales.

Cuadro 2: Efectos y Tiempo

\begin{tabular}{|c|c|c|}
\hline & Cronificacion & Coyuntura \\
\hline $\begin{array}{l}\mathrm{D} \\
\mathrm{e} \\
\mathrm{s} \\
\mathrm{t} \\
\mathrm{r} \\
\mathrm{u} \\
\mathrm{c} \\
\mathrm{c} \\
\mathrm{i} \\
\mathrm{o} \\
\mathrm{n}\end{array}$ & $\begin{array}{c}2.1 \\
\text { La crisis final }\end{array}$ & $\begin{array}{c}2.2 \\
\text { Destrucción periódica } \\
\text { (a lo Marx) }\end{array}$ \\
\hline $\begin{array}{l}\mathrm{R} \\
\mathrm{e} \\
\mathrm{g} \\
\mathrm{e} \\
\mathrm{n} \\
\mathrm{e} \\
\mathrm{r} \\
\mathrm{a} \\
\mathrm{c} \\
\mathrm{i} \\
\mathrm{o} \\
\mathrm{n}\end{array}$ & $\begin{array}{c}2.3 \\
\text { Modernidad como } \\
\text { riesgo continuo } \\
\text { (¿nuevo prudencialismo?) }\end{array}$ & $\begin{array}{c}2.4 \\
\text { Destrucción creadora } \\
\text { (a lo Schumpeter) }\end{array}$ \\
\hline
\end{tabular}

Fuente: Elaboración propia.

La primera matriz, que denomino de la Crisis Final (2.1), entrecruza la percepción de una crisis básicamente destructiva con la valoración de su carácter crónico. Se cree 
estar atrapado en una crisis que va minando y destruyendo el mundo legítimo en el que se vivía y que, comenzada, nunca acaba y por ello desespera. El resultado no puede ser sino una crisis final, un verdadero Juicio Último tras el cual lo que hasta entonces existente se disipe en la nada o sea limpiado por la Gran Justicia que está a la espera, tapada pero profetizada: la trompeta sonará pues no se puede vivir eternamente en la crisis.

También en el marco de una percepción de la crisis como destrucción sin sentido o sin finalidad/funcionalidad positiva, la variante que denomino de la Destrucción Periódica (2.2) combina esa destrucción con una percepción de un tiempo circular que se despliega en forma de ciclos repetitivos en los que las fases de relativo bienestar van seguidas por una destrucción ciega -y vuelta a empezar. Hay ecos de algunos de los análisis de Marx sobre el proceso de reproducción ampliada del Capital en esta matriz narrativa (Agnoletto, 2013; Osborne, 2010).

Distintas son las otras dos variantes que se asientan en la idea de una crisis que ofrece oportunidades, regenera y/o crea. La destrucción no es irracional, sino que se presenta como necesidad para generar novedades positivas. Eso puede ocurrir de manera continua. En tal caso estamos ante la matriz narrativa de la Modernidad como riesgo continuo (2.3). Se supone en este caso que, al modo de Baudelaire, la Modernidad supone la emergencia continua de novedades que convierten en obsoleto lo que hoy parece imperecedero; la discontinuidad, la inconstancia del mundo, en definitiva, la crisis, le son constitutivas, son su suceder propio, lo que siempre empieza y nunca acaba. El actor ha de aceptar esa continua renovación (es la experiencia misma de la Modernidad), pues supone creaciones o regeneraciones. Vive pues gestionando una perpetua crisis. Algunas experiencias del riesgo tienen este formato: el actor dice enfrentarse a un mundo no fiable e inestable, pero encuentra, justo en eso, un aliciente para convertir su vida en una superación continua de retos que resuelve por sí mismo (nuevo prudencialismo de los neo-foucaultianos, por ejemplo; véase O’Malley, 2004).

Por último, la variante que combina la crisis regeneradora-creativa con el deslizarse del tiempo en forma de ciclos es lógico denominarla de la Destrucción Creadora (2.4) al modo de Schumpeter (Smart, 2012). En este caso, el mundo es inestable, necesita regenerarse periódicamente, según ciclos de duración determinable, lo que lleva a que haya víctimas periódicas pero también a que se abran nuevas oportunidades. Esas oportunidades permiten la regeneración del sistema, la aparición de novedades que serán funcionales o reportarán bienes a nuevos sujetos. Pensado en términos de perdedores/ ganadores, esta experiencia de la crisis como destrucción creadora abre la posibilidad de un cambio social discontinuo, pero no catastrófico. La crisis es oportunidad para la renovación.

\section{Los sujetos de la narración}

Las matrices narrativas definen el punto de partida y el anclaje de narraciones posibles. El mundo tal como se muestra no está pre-narrado, sino que ha de ser reconducido a 
una trama que lo narre ${ }^{1}$ Las narraciones ciertamente acaban estando ahí, a la mano, para ser recogidas, recontadas y escuchadas. Están a disposición del hablante. Pero no hablan por sí mismas. Necesitan un narrador, una Sherezade que recogiendo motivos de aquí y allí, o explotando matrices disponibles, ponga lo acontecido como episodio de una narración. Pero Sherezade le cuenta algo sobre alguien a alguien, es decir, implica también un sujeto narrado y un receptor en relación al cual adquiere sentido lo que cuenta. La suma de narradores, narrados y receptores de la narración conforma lo que se denomina sujetos de la narración.

¿Quiénes son los narradores, los narrados y los receptores de las matrices narrativas de los grupos de discusión? Evidentemente sus propios miembros -y eventualmente el investigador que está presente y escucha. Pero no sólo ellos, pues lo que se cuenta no es sólo la propia historia, sino la historia de los demás -y es en esto en lo que la práctica de investigación de los grupos de discusión cobra especial ventaja sobre otras posibles. Es más, lo que se cuenta es la historia de los avatares de ese macro-sujeto que los empuja a contar que es la CRISIS misma, el punto ciego desde el que todo se mira y cuenta. En el marco de la historia de ese sujeto-cosa aparecen los sujetos narradores, narrados y receptores.

En este contexto interesan fundamentalmente los sujetos narrados, es decir, aquellos que aparecen en las matrices de las narraciones y cuya identidad (o cuyo ser-lo-queson) es puramente narrativa. Por esto entiendo que estos sujetos son lo que resulta de la historia que se cuenta -o puede contar- sobre ellos: se encuentran narrativamente 'sujetados'. Es evidente que los sujetos narrados pueden ser los narradores cuando hablan de sí, pero ni siempre ni típicamente. El repertorio de sentido a la mano fijado en la dinámica de los grupos de discusión induce a reconducirlos a cinco fundamentales, que se relacionan de manera compleja con las matrices narrativas individualizadas. Los denomino expresivamente: víctimas, afortunados, oportunistas, resistentes y aprovechados.

Las víctimas son objeto típico de la narración. Son los otros con los que se interactúa y cuyas historias se esbozan en las intervenciones sobre la crisis. Son la expresión máxima del actor-paciente y vulnerable. Lo que son y les pasa no lo han hecho, sino que les ha ocurrido o se han visto abocados a ello. Están más allá del límite que se pensaba imposible cruzar, expulsados de un mundo en el que vivían aparentemente seguros y no creían que se pudiera derrumbar. Son objeto de observación, más que de interactuación: la gente que rebusca en las basuras, o los que piden en las esquinas, o los que pierden el piso, o los amigos que ya no vienen al bar, o que no salen de casa porque les da vergüenza, etc. No son propiamente sujetos de derechos -como tales víctimas- sino objetos de conmiseración. Es más, para los sectores más desvalidos, es decir, para los narradores que se sienten menos protegidos y en peligro, son algo cercano: conocidos, parientes, gente del barrio, compañeros del trabajo. Incluso asoma

${ }^{1}$ Gil Calvo (2009: especialmente capítulo 4) ha analizado algunas de las estrategias narrativas utilizadas por los medios de comunicación para dar cuenta de (o construir mediáticamente) la crisis. Es evidente que los hablantes que analizamos reciben ecos de esos relatos mediáticos. Pero se trata de ecos que son re-significados y re-entramados. 
el temor de que la víctima puede acabar por ser uno mismo: el narrador se teme que, una vez más, las campanas estén doblando por uno mismo y que, en realidad, 'de te fabula narratur' y uno deba aplicarse el cuento.

-A mí me impresionó mucho una pareja buscando en un contenedor...

-Que hay gente que no tiene lo básico para vivir, y eso es muy triste

-Además ha pasado de gente que se manejaba bien.... (G2)

-Yo cada vez la veo más cerca la pobreza. Yo he visto gente buscando en el cubo de la basura, al lado de mi casa, que hace 5 años no lo veía.

-Yo también he visto bastante gente buscando en la basura. Y me parece... ¿hasta dónde vamos a llegar? (G3)

Es que ves esto y dices: es que te puede tocar a ti en cualquier momento, o sea, esto es como pito, pito gorgorito... yo a mí sí me preocupa. Y que tienes casos cerca, si no es tu primo, tu amigo, tu amiga... que ha pasado o algo, que se han quedado sin curro... (G5)

Los afortunados son privilegiados y así son reconocidos. Pero no viven en las partes nobles de la ciudad; su privilegio es sobrevivir en estos tiempos difíciles. En realidad son simplemente los que, pudiendo ser víctimas y no disponiendo de control sobre sus propias vidas, han sido regalados por la fortuna con el mantenimiento de su trabajo, su profesión, su pequeña empresa o un grupo familiar poco afectado por la crisis. Han reducido su estándar de vida; consumen menos; han tenido que renunciar a algunas cosas; y pasan miedo. Pero se consideran-y se presentan a sí mismos, ya que ésta es la posición más asumida, o a los que están en esa situación- como privilegiados, pues tienen lo que los otros han perdido o temen perder. No es que tengan mucho margen de actuación. Algunos han ganado más escudos para defenderse (funcionarios); mientras que otros consideran que se los tienen que forjar día a día (técnicos, autónomos); en cualquier caso, se reconocen poco pertrechados para combatir los avatares negativos de la fortuna. Es más, saben que no son sujetos potentes y agentes. Dependen, en realidad, de la suerte que puede serles -aunque no lo esperan- esquiva en el futuro. Su aspiración es mantenerse, quedarse como están, que la desgracia pase por delante sin fijarse en ellos. Su ansiedad es básicamente temporal: que pase o finalice de una vez lo que debería haber pasado o finalizado, es decir, la crisis. No se espera el paraíso al final, sino simplemente una vida decorosa y la esperanza de que el mundo no les sea hostil ${ }^{2}$.

"Yo creo que en otros..., primero, seguimos siendo unos privilegiados... 500

kilómetros al sur, esta conversación sería impensable...."(G1)

"Porque, vamos a ver, nosotros ya tenemos, más o menos la vida un poco encau-

zada. Pero ellos que están en la vida de emprender..."(G4).

${ }^{2}$ En este caso el sujeto narrado se aproxima o identifica con el narrador. Este habla de la gente de la sociedad, pero se pone a sí mismo como formando parte de ese colectivo de 'afortunados' o 'privilegiados' que, como tales, son los únicos capaces de contar lo que ocurre, de ser los voceros de la sociedad. 
"Yo confio en que la empresa de mi marido siga funcionando como hasta aho$r a . .$. es en lo que confio porque entonces ya sí que.., vamos, nos echamos a llorar... Afortunadamente, el trabajo está bien, no tiene ningún problema de crisis y demás, y eso es lo que me mantiene optimista... Entonces si se va eso... vamos. Es en lo que confío ahora mismo" (G4).

"A nivel personal yo te diría que yo, pues sí que me considero un privilegiado, bueno porque tengo lo que tengo y creo que tengo la vida resuelta... Creo, toco madera. Pero vamos, privilegiado ninguno. Yo trabajar he trabajado toda mi vida, imagínate, para luego tener 34 días de vacaciones y demás. Pero bueno la situación económica, la tengo solventada, yo pienso..." (G6).

"Estamos en colectivo que somos unos privilegiados [...] Vivimos en un oasis. Somos unos privilegiados" (G7).

“... y de mi generación, poca gente hay que tenga la suerte que tengo yo de poder trabajar" (G7).

Los oportunistas pueden ser calificados así en razón de que, aunque no hayan sido agentes autónomos desde el principio, la crisis les abre una oportunidad para hacer cosas que anteriormente no eran factibles o resultaban incluso impensables. En algunos casos, ya las están haciendo; pero aun más relevante son sus expectativas, especialmente el hecho de que imaginen que la crisis les valdrá para explorar nuevos mundos, hacer cosas nuevas, dedicarse a actividades en las que no habían pensado, remodelar en términos positivos su propia vida. Para este sujeto del relato de un mundo básicamente imaginado, la crisis es una oportunidad: ya sea para enfrentar su propia vida y tomar decisiones que en un mundo más estable no tendría que tomar por estar todo hecho; ya sea para explorar cosas nuevas y construir un mundo diferente. Si contraponemos narración (que trata de lo ocurrido y se refiere a algo ya hecho y pasado) e imaginación (que hace referencia a algo no acontecido, pero que se contempla como un futuro perfecto o pasado futuro), entonces lo propio de los oportunistas es que, más que narrar, imaginan, es decir, cuentan historias del futuro -lo que, en un principio, no se puede narrar ${ }^{3}$. Son quienes encarnan la cara positiva del cambio.

Pero no me refiero a comportamiento, me refiero a la forma de ver las cosas. Precisamente los que están muy preparados.

-[Hablan a la vez]

-Tienen una visión que no teníamos nosotros...

-Eso es, es distinto

-Hay más posibilidades. Yo también pienso que en el futuro (...) (G1)

"Ahora tienes que estar muy bien preparado. Aun así, aunque tengas muy buena preparación, pues tienes que estar en el momento oportuno, en el sitio oportuno.... Bueno que hay muchas variables que yo creo que antes no se daban o bueno era más fácil conseguirlo o había más oportunidades" (G2)

${ }^{3}$ La relevancia de esta distinción narrar/imaginar para dar cuenta de los discursos sociales sobre la crisis ha sido reivindicada por Vigh (2008) para el estudio de los discursos sociales sobre la crisis crónica. 
"Yo creo que no puedes dar por hecho que nada es para toda la vida. Tú tienes que intentar, lo que quieras conservar, conservarlo, pero tienes que estar preparado, porque nunca se sabe..." (G3)

"Hago estudios de mercado, domo caballos, aparte todos los días me cuido, corro 10 kilómetros, hago mi ejercicio, y luego, aparte, hago publicidad, hago de modelo. Eso me lleva a una conclusión, todo lo que hagas en esta vida nunca es suficiente, porque si solo te dedicas a una cosa y te va mal, te va a costar levantar la cabeza siempre. Entonces cuantas más cosas hagas, más te vas valer por ti mismo y más oportunidades vas a tener. Yo es lo que veo en mi experiencia personal" (G9)

Los resistentes se sitúan parcialmente en el polo de la paciencia, pues su situación no es hija de sus obras. Pero son conscientes de que hay que resistir, oponerse, actuar, movilizarse. Quieren, pues, ser actores-agentes. No tienen la sensación de formar parte de un sujeto colectivo previo, compacto, tal vez algo adormilado, pero capaz de despertarse. Por el contrario, suponen que la acción colectiva ha de ser construida, es decir, que no está potencialmente disponible a la espera de ser actualizada: no hay un tren del 'pueblo' o de los 'trabajadores' o del 'proletariado' ya en marcha al que subirse. De ahí, un cierto desánimo por la falta de compromiso de la 'gente', pero también la confianza en que si no se cae en el desánimo, si se da testimonio y se resiste, al final la gente luchará por sus derechos y reorientará la crisis. Así lo hicieron los abuelos y los padres en tiempos muy difíciles; así se puede volver a hacer ahora.

Pero volvemos a lo mismo, es que no te preguntan. Es que ponen el AVE y nadie te pregunta si lo quieres o no. Y te cierran, y te cierran y por mucho que están... ahí en Salamanca están a tortas, porque les están cerrando las urgencias que las tienen a 100 kilómetros por unas carreteras que te mueres y se las cierran y punto

-¿Pero por qué te van a preguntar? quiero decir, ¿hay alguna...? ¿Por qué nos van a preguntar? Si no pasa nada sin preguntarnos (...)

-Es que sí que pasa, están manifestados. Están encerrados en los centros de salud para que (...) (G1)

"De hecho salía en el video, que salía la gente por la calle y decía, es que es lógico, yo no tengo porqué pagar a esos señores." (G4)

"Yo sigo pensando que nuestros padres, todo lo que consiguieron, pasaron de estar aquí, lucharon mucho, lucharon, les costó muchísimo hasta que llegaron a tal, y nosotros somos los hijos, la generación que no hemos hecho nada en realidad, nos lo han dado hecho." (G5)

"Cada día tienes que defender tus derechos, tus cosas... Pues el que esté en la empresa tendrá que defender lo suyo, dentro de su propia empresa. ¿Es triste? Sí muy triste. Sí, pero es que la vida es así. Es,...continuamente tienes que estar luchando y berreando por lo tuyo." (G7)

"Yo confío, a lo mejor, cada vez más en la gente, la gente se está volviendo más social, intenta ayudar a la gente.... Ya en el tema de desahucios y tal, ves cómo hay 
gente que se une para luchar contra ello... a lo mejor no es su casa y no conocen a la persona pero, como que ya se van uniendo." (G9)

Por último, los aprovechados son aquellos que con sus acciones tienen una alta responsabilidad en la crisis, sobre todo en su dirección y alargamiento. No se pretende que sean ellos sus verdaderos causantes. La crisis es algo que posiblemente nadie ha querido y todos han encontrado; es una cosa-sujeto autónomo, como se propuso antes. Pero una vez estallada, cabe fijar culpables y aprovechados. Los culpables son los que jugaron con ladrillos, préstamos y burbujas hasta generar la catástrofe. Sus intereses los llevaron a poner en riesgo a todos. Los aprovechados son los que, una vez desatada la crisis, intentan sacar partido de la situación utilizando las necesidades de los demás en su propio provecho; utilizan sus posiciones de poder para sacar partido; se ponen a la sombra de la crisis y en ella hallan cobijo para sacar partido, para abusar. Son, en definitiva, los verdugos; y no hay verdugo sin víctima.

"Yo creo que cada vez más está estirándose más hacia una clase elitista, que vivir bien, muy bien. Y esa clase media va a desaparecer. Que eso sí que va a ser jodido. Eso sí que lo veo un futuro, que todo tiende hacía eso. No que todo se reparta mejor, sino que se reparta peor. Menos trabajo, más precariedad, más sacar beneficios (...)" (G1)

"Están en ERES y están teniendo beneficios. Es que es una cosa que yo no entiendo. Si el Estado te está pagando para que tú no cierres, y encima estás ganando más que cuando tenías a todos tus empleados. A mí es que estas cosas (...)" (G3)

"Es que ellos han dicho de cambiar algo... Ellos solamente hablan: más beneficios y menos beneficios.... Mientras aqui es comer, o no comes (...)" (G4)

"También te pones a pensar y por culpa... bueno por culpa.... Porque se aproveche por la crisis recortan y ya no sabes ni lo que estás comiendo (...) (G5)

"-Hago un presupuesto el otro día, y he llegado y ¿el futuro cómo lo ves? (...) Oye, 2.300 pavos (...) es que tengo uno de mil. ¿Tienes uno de mil? (...) que te lo haga $(\ldots)$

-Claro.

-¿Cómo que te lo haga? Sí... Y ayer me viene y dice: Oye vas a hacerlo tú porque como te conocemos y es más confianza (...) Digo (...) coño (...)

-Se está abusando.

-Abusan.”(G6)

Lo primero que salga lo tienes que coger, te guste o no te guste, te paguen bien o te paguen mal. Incluso sabes que te están explotando, y te tienes que callar.(G9)

\section{Conclusiones}

En su monumental Temps et récit, Paul Ricoeur (1983-5) propone que la herida del tiempo sólo se puede suturar con relatos. Un relato entrama escenarios, personajes y episodios de forma tal que lo que va pasando y carcome las cosas se engarza, se aúna y al final queda tipificado como un caso de las historias que forman parte de nuestro repertorio cultural de sentido. De este modo, disponer de una narración en la 
que situar lo que sucede dota de sentido a la experiencia del tiempo: contar (o poder contar) algo es ya hacerlo comprensible. Podemos reinterpretar en el marco de estas ideas las propuestas, mucho más modestas y de menor vuelo, de Janet Roitman. Si, como asegura recogiendo los argumentos de Koselleck, la crisis es la constante de la Modernidad, aquello con lo que nos tropezamos continuamente, aquello que deslegitima y carcome todo lo sólido y hace que se desvanezca, entonces es lógico que sea también la narración, con sus operaciones típicas de entramado, la que permita darle sentido.

Atendamos también al hecho de que la emergencia narrativa del sentido va siempre de la mano de la actualización de un juicio moral. White (1990) ha sostenido, inspirándose en Hegel, que narrativizar algo es ipso facto someterlo a un juicio moral en el que se contrasta implícitamente lo que ha ocurrido (o lo que ocurre) con lo que debería ocurrir si el universo moral en que vivimos se realizara efectivamente. De ahí el tinte moral muy cargado, no sólo de las matrices-tramas narrativas, sino también de los personajes o sujetos que se presentan en las narraciones.

En este trabajo se han propuesto las matrices estructurales de las narraciones implícitas de la crisis que usan los hablantes para enmarcar sus intervenciones. Es así como se han fijado un número, más amplio que el propuesto por Roitman, de matrices narrativas. No agotan el mundo de lo posible, ni siquiera el mundo de lo que efectivamente se va diciendo. Pero son suficientemente potentes como para esbozar el núcleo duro de las narraciones recurrentes. Un análisis más ambicioso podría reconducir las ocho matrices diferenciadas al modelo canónico de tramas propuesto por Frye (1977) y White (1987). En realidad, las matrices no son sino expresiones más o menos puras de las tramas prototípicas de la comedia, la tragedia, el romance y la sátira. Nos limitamos aquí a adelantarlo a la espera de demostrarlo en una investigación ulterior.

En el marco de las matrices narrativas están los narradores y los narrados. Ambos son sujetos en pos de una identidad narrativa, es decir, temporal (secuencia, sentido de un final, etc.), fenoménica (las cosas que van ocurriendo) y entramada (la trama que selecciona, aúna y tipifica). Los tipos diferenciados son suficientemente expresivos como para dar cuenta de lo que en esos mundos se ventila, que no es otra cosa que la evidencia de que lo que uno es se despliega en el tiempo a lo largo de una secuencia de acontecimientos (cumplidos o por venir) a los que se asigna sentido recurriendo al repertorio de que se dispone y está a la mano, e insertándolo en las matrices narrativas disponibles. Los tipos permiten también enjuiciar moralmente el mundo enfrentado, condenando a uno (aprovechados), ensalzando a otros (resistentes), distanciándose de otros, ya sea doliéndose de su suerte (víctimas), ya sea admirándolos aunque en tono -moralmente- menor (oportunistas) y celebrando, al final, la supervivencia de algunos (afortunados) a los que una suerte esquiva ha preservado del infortunio.

\section{Bibliografía}

Agnoletto, S. (2013): "Periodic Crises in Capitalism: Pathological or Restorative?" Science \& Society, 77 (4), pp. 459-485.

Arendt, H. (1993): La condición humana, Barcelona, Paidos Beck, U. (1998): Políticas ecológicas en la edad del riesgo, Barcelona, El Roure. 
Carroll, N. (2005): Filosofia del terror o paradojas del corazón, Madrid, Antonio Machado.

Castells, M., J. Caraça y G. Cardoso (eds.) (2013): Después de la crisis, Madrid, Alianza.

Clarke, J. (2010): "After neo-liberalism? Markets, states and the reinvention of public welfare", Cultural Studies, 24 (3), pp. 375-394.

Clarke, J. (2010): "Of Crises and Conjunctures: The Problem of the Present", Journal of Communication Inquiry, 34 (4), pp. 337 -354.

Clarke, J. y J. Newman (2010): "Summoning spectres: crises and their construction", Journal of Education Policy, 25 (6), pp. 709-715.

Freund, J. (1976): "Observations sur deux catégories de la dynamique polémogène. De la crise au conflit", Communications, 25, pp.101-112.

Frye, N. (1977): Anatomía de la crítica, Caracas, Monte Ávila.

Gil Calvo, E. (2009): Crisis crónica. La construcción social de la gran recesión, Madrid, Alianza.

Gil Calvo, E. (2013): Los poderes opacos: austeridad y resistencia, Madrid, Alianza Editorial.

Grossberg, L. (2010): “Modernity and commesuration", Cultural Studies 24 (3), pp. 295-332.

Gunder Frank, A. (1983): "Crisis de la ideología e ideología de la crisis", en S. Amin et al., Dinámica de la crisis global México, Siglo XXI, pp. 119-177.

Hayward, M. (2010): "The economic crisis and after: recovery, reconstruction and cultural studies", Cultural Studies, 24 (3), pp. 283-294.

Kermode, F. (1983): El sentido de un final, Madrid, Gedisa.

Koselleck, R. (2007): Crítica y crisis. Un estudio sobre la patogénesis del mundo burgués, Madrid, Trotta.

Koselleck, R. (2012) Historias de conceptos. Estudios sobre semántica y pragmática del lenguaje político y social, Madrid, Trotta.

Lockwood, D. (1964): "Social integration and system integration", en G.E. Zollschan y W. Hirsch (eds.), Social Change, New York, Houghton Mifflin, pp. 244-257.

Mennell, S. (2014): "What economists forgot (and what Wall Street and the City never learned). A sociological perspective on the crisis in economics", History of the Human Sciences, 27 (3), pp. 20-37.

Mishra, R. (1982): “ System Integration, Social Action and Change: Some Problems in Sociological Analysis", Sociological Review, 30 (1), pp. 5-22.

Morin, E. (1976): "Pour une crisologie", Communications, 25, pp. 149-163.

Morin, E. (1995): Sociología, Madrid, Tecnos.

Mouzelis, N. (1997): "Social and System Integration: Lockwood, Habermas, Giddens", Sociology, 31 (1), pp. 111-119.

O’Connor, J. (1989): El significado de la crisis: una introducción teórica, Madrid, Revolución.

O’Malley, P. (2004): Risk, Uncertainty and Government, London, Cavendish/ Glasshouse. 
Osborne, P. (2010): "A sudden topicality: Marx, Nietzsche and the politics of crisis", Radical Philosophy, 160, pp. 19-26.

Ramos Torre, R. y J. Callejo Gallego (pendiente de publicación): "Semántica social de la crisis: repertorio de sentido a la mano", en Tejerina, B. y G. Gatti.

Ricoeur, P. (1983-5): Temps et récit I, II y III, Paris, Seuil.

Roitman, J. "Crisis" (2011): Political concept: a critical lexicon. Disponible en: http://www.politicalconcepts.org/issue1/crisis/

Roitman, J. (2014): Anti-crisis, Durham y London, Duke University Press.

Shank, J.B. (2008): "Crisis: a useful category of post-social scientific analysis", American Historical Review, 113 (4), pp. 1090-99.

Smart, B. (2012): "Fiscal crisis and creative destruction: Critical reflections on Schumpeter's contemporary relevance", Journal of Classical Sociology, 12 (3-4), pp. 526-543.

Starn, R. (1971): "Historians and 'Crisis"”, Past and Present, 52, pp. 3-22.

Sztompka, Piotr (1984): "The Global Crisis and the Reflexiveness of the Social System", International Journal of Comparative Sociology, 25 (1-2), pp. 45-58.

Vigh, H. (2008): "Crisis and chronicity: anthropological perspectives on continuous conflict and decline", Ethnos, 73 (1), pp. 5-24.

Wieviorka, M. (2013): “Crisis financiera o cambio social?”, en M. Castells, J. Caraça y G. Cardoso (eds.), Después de la crisis, Madrid, Alianza, pp. 127-154.

Williams, R. (2013): "El arrollador apocalipsis de la historia contemporánea", en M. Castells, J. Caraça y G. Cardoso (eds.), Después de la crisis, Madrid, Alianza, pp. 42-75.

White H. (1987): Metahistory. The historical Imagination in Nineteenth-Century Europe, Baltimore, The John Hopkins University Press.

White H. (1990): The Content of the Form, Baltimore, The John Hopkins University Press. 